OPEN ACCESS

Edited by:

Peng He,

Guizhou University, China

Reviewed by:

Ping Wen,

Xishuangbanna Tropical Botanical

Garden (CAS), China

Hong-bin Wang,

Research Institute of Forest Ecology, Environment and Protection (CAF),

China

${ }^{*}$ Correspondence:

Rui Tang

tangrui@ioz.ac.cn;

minamo@163.com

${ }^{\dagger}$ These authors have contributed

equally to this work

¥ORCID:

Rui Tang

orcid.org/0000-0002-9313-0802

Specialty section:

This article was submitted to Invertebrate Physiology,

a section of the journal

Frontiers in Physiology

Received: 06 February 2020 Accepted: 21 April 2020 Published: 29 May 2020

Citation:

Bai P-H, Wang H-M, Liu B-S, Li M, Liu B-M, Gu X-S and Tang R (2020) Botanical Volatiles Selection

in Mediating Electrophysiological

Responses and Reproductive Behaviors for the Fall Webworm Moth

Hyphantria cunea.

Front. Physiol. 11:486.

doi: 10.3389/fphys.2020.00486

\section{Botanical Volatiles Selection in Mediating Electrophysiological Responses and Reproductive Behaviors for the Fall Webworm Moth Hyphantria cunea}

\author{
Peng-Hua Bai ${ }^{1,2+}$, Hong-Min Wang ${ }^{3+}$, Bao-Sheng Liu ${ }^{1}$, Min Li $^{4}$, Bai-Ming Liu' ${ }^{1}$ Xi-Shu Gu ${ }^{1}$ \\ and Rui Tang ${ }^{2,5 * \neq}$

\begin{abstract}
'Institute of Plant Protection, Tianjin Academy of Agricultural Sciences, Tianjin, China, ${ }^{2}$ State Key Laboratory for Biology of Plant Diseases and Insect Pests, Institute of Plant Protection, Chinese Academy of Agricultural Sciences, Beijing, China, ${ }^{3}$ College of Economics and Management, Shanxi Agricultural University, Taigu, China, ${ }^{4}$ Tianjin Key Laboratory of Animal and Plant Resistance, Tianjin Normal University, Tianjin, China, ${ }^{5}$ State Key Laboratory of Integrated Management of Pest Insects
\end{abstract} \\ and Rodents, Institute of Zoology, Chinese Academy of Sciences, Beijing, China
}

Host-plant volatiles play vital roles for insects to locate foraging, mating, and oviposition sites in the environment. As one of the devastating invasive forestry pests, Hyphantria cunea causes a great annual loss in China, and understanding its chemical ecology is an important task. The current research was done in terms of chemical analysis, electrophysiology, and behavioral assays on $\mathrm{H}$. cunea to assess its olfactory reception toward host-plant volatiles. A screen of possible common host volatiles was done, targeting on five favored hosts of $H$. cunea, harvesting six potential bioactive compounds from a total of 78 odorant components. Six types of antennal sensilla were investigated on their distributions on the antennae, and sexual dimorphism was described. H. cunea showed responses to all selected host-related volatiles in electroantennogram tests, and linalyl butyrate elicited the strongest responses. Furthermore, mating rates in adult pairs that are exposed to dibutyl phthalate and phytol have been significantly increased, while oviposition rates and female fecundity were not influenced. The results of the current study provide initial evidence showing that universal host-derived volatile cues are essential for $\mathrm{H}$. cunea moth in terms of mating, which can also provide insights into the development of botanical attractants.

Keywords: Hyphantria cunea, host volatiles, GC-MS, SEM, electroantennogram, reproductive behavior

\section{INTRODUCTION}

In recent years, there have been extensive studies on the role of plant-derived compounds that regulate interactions between herbivorous insects and their host plants (Joseph and Carlson, 2015; Bisch-Knaden et al., 2018; Turlings and Erb, 2018; Guo and Wang, 2019). Several studies have shown that plant volatiles play a significant role in mating and host recognition in phytophagous insects by influencing antennal sensitivities to chemical components (Xu et al., 2001; Reed and Landolt, 2002; Natale et al., 2004; Bleeker et al., 2011; Gundappa et al., 2016). Various works have 
indicated that host-derived volatiles were successfully deployed in the management of agricultural and forestry pests by the development of botanical attractants, push-pull strategies, and modulation of reproductive behaviors. The botanical attractants based on volatiles from host plants are known to effectively attract both sexes of herbivorous insect pests, which plays an important role in monitoring and control of insect pests including Bactrocera dorsalis, Helicoverpa armigera, Cydia pomonella, and Frankliniella occidentalis (Light et al., 2001; Li et al., 2005; Siderhurst and Jang, 2006; Singh and Mullick, 2010; Abdullah et al., 2015; Gregg et al., 2016). The push-pull strategies with botanical volatiles have also been widely utilized in pest control, for instance, Delia radicum in cabbage, Diaphorina citri Kuwayama in citrus, and Aphididae species in wheatpea strip (Kergunteuil et al., 2015; Yan et al., 2015; Xu et al., 2018). Furthermore, several studies have shown that the chemical composition of host plant plays an integral part in mating and oviposition behaviors in various insects, including Lepidoptera, Hemiptera, and Coleoptera (Shelly, 2001; Paschen et al., 2012; Juma et al., 2016).

The fall webworm Hyphantria cunea (Durry) (Lepidoptera: Arctiidae) is a devastating invasive insect that is native to North America. H. cunea was first recorded in Liaoning Province in China in 1979 and later it has widely expanded its distribution to Beijing, Tianjin, Hebei, Shandong, Shanxi, Jiangsu, and Anhui provinces (Yang et al., 2006; Chen et al., 2014; Zhang et al., 2016a). It has been reported that the occurrence of $H$. cunea in China reached a $20.9 \%$ annual increase, and this pest has been causing massive damage to forests, orchards, and even crops because of its polyphagous trait (Yang et al., 2006; Su et al., 2008; Zhang et al., 2016b). Currently, more than 400 plant species are recorded to serve as hosts for $H$. cunea worldwide (Schowalter and Ring, 2017). Several methods including biopesticides, parasitoid wasps, and sex pheromone traps have been used to monitor and control H. cunea (Su et al., 2008; Yang et al., 2008; Kim et al., 2011; Saruhan et al., 2014). Specifically, due to its TYPE II sex pheromone structures, synthetic pheromone luring of $H$. cunea was applied at a higher cost than other lepidopteran pests (Hill et al., 1982; Su et al., 2008; Schowalter and Ring, 2017). Sex pheromone monitoring of $H$. cunea in China nowadays has been solely dependent on imported luring products, which raised the demands of developing botanical attractants/synergists or related push-pull strategy for large-scale IPM needs (Bai et al., 2017).

There has been less previous evidence regarding the influences of plant volatiles toward $H$. cunea. Some volatile compounds from host plant (Morus alba, Malus spectabilis) and areadependent non-host plant (Robinta pseudoacacia) have been identified (Tang et al., 2012; Bai et al., 2018a,b). Given the fact that this polyphagous pest may infest different plant hosts in its habitats depending on local vegetation distributions (Yang et al., 2010), screen for universal host cues can help to explore the chemical ecology of this moth. On the other hand, recent research has reported morphology of its antennal sensilla, but information on the distribution of sensillar types has not yet been tackled (Zhang et al., 2019). To date, a number of questions on olfaction of $H$. cunea, such as its key host volatiles as well as the electrophysiological sensitivity on antennae and how plant volatiles affect its reproductive behaviors, remain to be answered. In the current work, we identified 78 host volatile compounds from five favored host species of $H$. cunea in China and narrowed down to six key components for later tests. The distributions of six sensilla types on antennae of $H$. cunea were investigated by scanning electron microscopy (SEM). Later, the electroantennogram (EAG) test against selected host-plant odorants has been used to investigate the sensitive volatiles that have potential effects on the behaviors. To test the reproductive behavioral responses of $H$. cunea to volatile compounds associated with host plants, we studied the effects of sensitive volatiles on the mating and oviposition of $H$. cunea. The results from the current research can provide insights into a better understanding of the olfactory perception of $H$. cunea. Moreover, selection of the effective botanical components can be used for future utilizations as a botanical attractant and pheromone synergetics in ecological-based control of this devastating pest in the fields.

\section{MATERIALS AND METHODS}

\section{Insects and Plants}

$H$. cunea were obtained from the Chinese Academy of Forestry, where a laboratory population of $H$. cunea using wild moths was established from Qinghuangdao, Hebei Province, China. The pupae were stored in a climate chamber at $25 \pm 1^{\circ} \mathrm{C}$ and R.H. 50-60\% under a 16L:8D photoperiod until emergence. Newly emerged moths were immediately separated by gender and kept at a density of five adults per 500-ml beaker with 5\% sugar solution provided. One- to three-day-old virgin moths were fasted for 3-6 $\mathrm{h}$ before being used in electrophysiological and behavioral tests.

Plant leaves from M. alba, Fraxinus chinensis, Populus alba, Ailanthus altissima, and M. spectabilis were collected in forestry experimental sites of the Tianjin Institute of Plant Protection in Wuqing, Tianjin $\left(39^{\circ} 25^{\prime} 33.3^{\prime \prime} \mathrm{N}, 116^{\circ} 57^{\prime} 35.7^{\prime \prime} \mathrm{E}\right)$. Leaf samples were immediately brought back to the lab where extraction process was carried out within 1 day.

\section{Chemical Analysis}

Tested leaf samples were cut into fine pieces and boiled with water with $1: 1 \mathrm{w} / \mathrm{w}$ for $4-6 \mathrm{~h}$ to prepare the water distillations, followed by extraction with hexane. Upper phases of the extracts were then collected and desiccated with anhydrous sodium sulfate drying agent columns. Prepared essential extracts were analyzed at $1 \mathrm{ml} / \mathrm{min}$ through an Agilent Technologies 5973MD mass spectrometer coupled with an Agilent Technologies 6890N gas chromatography system (Santa Clara, CA, United States) equipped with a quartz capillary column (HP-5MS, $30 \mathrm{~m} \times 0.25 \mathrm{~mm} \times 0.25 \mu \mathrm{m}$; J\&W Scientific, Palo Alto, CA, United States). Volatile traces were identified by crosschecking with the mass spectrum fragment database (NIST 2.0) with GC/MSD ChemStation (Agilent) and selected 
components for later tests were confirmed against standard chemical spectrum patterns.

\section{Scanning Electron Microscopy}

The antennae from the head capsule of emerged adults ( $n=12$; sex ratio, $1: 1)$ were placed in $2 \%$ glutaraldehyde solution fixed overnight at $4{ }^{\circ} \mathrm{C}$. After three washes at room temperature with $0.1 \mathrm{M}$ PBS, antennae were incubated for $2 \mathrm{~h}$ at $4^{\circ} \mathrm{C}$ and then washed three times with $0.1 \mathrm{M}$ PBS. The specimens were dehydrated through a series of graded ethanol $(30,50,70,80$, and $90 \%)$, followed by three washings in $100 \%$ ethanol. After drying in a critical point drier (BalTel CPD 030), antennae were mounted on aluminum stubs, taking care to place them with different orientations, to obtain views of the ventral and dorsal aspects and of both of the lateral sides. Then, the mounted specimens were sprayed with gold (Bal-Tel SCD 005) and observed with SEM (FEI Quanta 200). The sensilla were classified according to their morphology, shape, and size, following Schneider (1964) and Zacharuk (1980).

\section{Chemicals}

The $11 \mathrm{M}$. alba-related volatiles were previously identified (Tang et al., 2012), and they were selected in this study as references for the later chemicals; detailed information can be found in Supplementary Table S1. The reason we put these 11 chemicals in the comparison was that they were from the favorite plant of $H$. cunea and they compose a full spectrum of bioactive volatiles of this host species toward the pest. We suggested that the amplitudes elicited by these chemicals may provide a baseline response for investigation on the newly tested six volatiles in this work. The six additional components (phytol, $\mathrm{n}$-pentatriacontane, linalyl butyrate, palmitic acid, $\alpha$-linolenic acid, and dibutyl phthalate, all 95\% minimum purity) used in this study were selected by either referring to the GC-MS results or to the studies on host plant $M$. spectabilis and areadependent non-host plant $R$. pseudoacacia of $H$. cunea (Bai et al., 2018a,b). All of these six synthetic standard components were obtained from Meryer Chemical Technology Co., Ltd. (Shanghai, China). For EAG experiment, the components (phytol, linalyl butyrate, $\alpha$-linolenic acid, dibutyl phthalate, and other $11 \mathrm{M}$. alba volatiles) were dissolved in paraffin oil for dosage response trials $(10 \mu \mathrm{l}$ applied to a $0.8 \times 2 \mathrm{~cm}$ filter paper with concentrations at $0.001,0.01,0.1,1,10 \mu \mathrm{g} / \mu \mathrm{l}$, respectively), and $\mathrm{n}$-pentatriacontane and palmitic acid were dissolved at the same dosages in hexane as they were insoluble in paraffin oil. The other 11 reference volatiles were prepared at four concentrations of $0.1-100 \mu \mathrm{g} / \mu \mathrm{l}$ (equal to $1-1000 \mu \mathrm{g}$ in dosages). The dosages of the six components for mating and oviposition experiments were decided according to the results of the EAG experiment.

\section{Electrophysiology}

The EAG method was adopted to test the receptivity of the antenna of male and female moths to the volatile compounds. Each antenna was carefully excised at both extremes and immediately placed within the indifferent electrodes with Spectra
360 conductive gel. The signals were passed through an IDAC2 data acquisition controller unit and recorded by a computer using a software package (Syntech, Kirchzarten, Germany). The stimulus was delivered into a purified air stream $(30 \mathrm{ml} / \mathrm{s})$ by a gas control unit (Syntech CS-55). The gas outlet faced the antenna with $1 \mathrm{~cm}$ distance from it. For each sample, $10 \mu \mathrm{l}$ was applied to a $0.8 \times 2 \mathrm{~cm}$ filter paper in a Pasteur pipette. Antenna from both sexes of $H$. cunea were stimulated for $0.8 \mathrm{~s}$ with an interval time of $30 \mathrm{~s}$. The same antenna was used to test all of the concentrations of a single compound. Each concentration was tested with six different antennae per gender. The sequence of the tested compound was provided starting from the weakest concentration and followed by increasing concentrations. The control was added before and after stimulation by each concentration of the tested compounds. Recorded EAG data were fed into IDAC-2 and analyzed with EAG 2000 software (Syntech).

\section{Reproductive Behavioral Response}

To evaluate the reproductive behavioral responses of moths to plant-derived volatiles, single-pair courtship assays were used. We observed the effect of the electrophysiologically active compounds (at the concentration that elicited the strongest EAG response) on mating and oviposition of $H$. cunea. Green rubber septa (The West Company, Phoenixville, PA, United States) were loaded with $100 \mu \mathrm{l}$ of the tested volatile mixtures at the selected concentration. Septa containing $100 \mu \mathrm{l}$ of solvent and a blank septum were used as controls. A pair (one male, one female) of 1- to 3-day-old virgin moths was placed in a beaker $(500 \mathrm{ml}, d=9.4 \mathrm{~cm}, h=12.4 \mathrm{~cm})$ together with one septum at $25 \pm 1^{\circ} \mathrm{C}$, R.H. $50-60 \%$, and $16 \mathrm{~L}: 8 \mathrm{D}$. The number of pairs that mated within $24 \mathrm{~h}$ was observed and counted. Mating rate was defined as the proportion of the mated pairs in $10-15$ pairs tested independently, and oviposition rate indicates proportion of mated females that performed oviposition behaviors. Finally, egg numbers were counted after $48 \mathrm{~h}$ in oviposition female pairs as female fecundity. A total of four replicates were conducted for each treatment.

\section{Statistical Analysis}

The EAG data were standardized to include background influences of solvents before means \pm SEM were calculated for parametric tests. Specifically, the relative EAGs to a test stimulus ( $\mathrm{Sr}$ ) were calculated as $\mathrm{Sr}=2 \mathrm{Sc} /\left(\mathrm{R}^{\prime}+\mathrm{R}^{\prime \prime}\right)$, where $\mathrm{Sc}$ is the absolute amplitude of the stimuli and $\mathrm{R}^{\prime}$ and $\mathrm{R}^{\prime \prime}$ are the mean responses to the reference substances before and after stimulation (Hou and Yan, 1995; Zhu et al., 2017). The same data of each chemical at $10 \mu \mathrm{g}$ were used in both baseline comparison and dosage comparison. Means \pm SEM were calculated for measurement data (sensilla parameters) and proportion data (behavioral tests) before testing in a parametric model. Counts data for sensilla were tested with chi-square tests. Statistics for means were analyzed with either two-tailed $t$-test (two treatments) or two-tailed GLM ( $>2$ treatments) followed by Dunnett against controls or Tukey HSD at $P=0.05$. SPSS version 17.0 (IBM, Chicago, IL, United States) software was used for statistical analysis. 


\section{RESULTS}

\section{Common Volatiles in Five Favored Host Plant}

A total 78 components were identified through GC-MS approach in the extracts of host plants for $\mathrm{H}$. cunea (Figure 1). Most of the components existed in only one to two blends, but phytol and $\alpha$-linolenic acid were observed in the GC-MS traces of all five blends from $M$. alba, F. chinensis, $P$. alba, A. altissima, and M. spectabilis. $\alpha$-Linolenic acid occupied the highest proportion of $17.73 \pm 5.6 \%$ (mean \pm SEM) in the volatiles, and phytol was the second highest at $10.6 \pm 4.9 \%$. Palmitic acid existed in four of five plant volatile blends including $M$. alba, F. chinensis, $P$. alba, and A. altissima, occupying overall $9.8 \pm 4.5 \%$ of the blends. 2-Methoxy-4-vinylphenol was also observed in four plants of M. alba, P. alba, A. altissima, and M. spectabilis with covering $7.73 \pm 3.16 \%$ of the volatiles. Diacetone alcohol was also found in M. alba, F. chinensis, $P$. alba, and A. altissima with a proportion of $1.96 \pm 0.80 \%$. Based on these results, we suggested that the top three components including phytol, $\alpha$-linolenic acid, and palmitic acid may have vital roles in host communications of $H$. cunea as they were the most common and abundant volatiles in the tested favored host plants. We then decided to include these three chemicals in the successive tests. The main reason for selecting the other $\mathrm{n}$-pentatriacontane, linalyl butyrate, and dibutyl phthalate for testing was based on our previous works which revealed their potentially high electrophysiological activities toward H. cunea (Bai et al., 2018a,b). We sought to find whether some behavioral/ecological significance of these six chemicals can be otherwise exhibited in the later trials.

\section{Sensillar Types and Distribution}

The antenna of $H$. cunea moth is composed of the scape, pedicel, and flagellum; the flagellum of the female is composed of 3442 sub-segments (mean $\pm \mathrm{SEM}=40 \pm 0.95$ ) and that of the male is 35-42 (38.6 \pm 1.24$)$ (Supplementary Figures S1A-D). The estimated length of the flagellum was $5467 \pm 247.0 \mu \mathrm{m}$ for males and $5644.3 \pm 151.3 \mu \mathrm{m}$ for females. No difference was observed between genders in terms of length of flagellum (Supplementary Figure S1E) ( $t$-test, $\left.t_{10}=0.61, P=0.55\right)$. The SEM investigations of the antenna revealed six types of sensilla, including sensilla chaetica, sensilla trichodea, sensilla basiconica, sensilla coeloconica, sensilla squamiformia, and sensilla böhm bristles (Supplementary Figure S2). The antennal morphology and types of sensilla as well as identifiers in $H$. cunea are identical with recently reported works on the same species (Zhang et al., 2019).

Distributions of sensilla types were not even between genders, and males bear significantly more sensilla trichodea per antenna than females (Figure 2A) (chi-square test, $\chi_{4}=405, P<0.0001$ ), indicating its potential role in sex pheromone olfactory reception. Males had significant longer sensilla trichodea $\left(t\right.$-test, $t_{10}=2.57$, $\left.{ }^{*} P=0.028\right)$ and shorter sensilla chaetica than female adults (Supplementary Figure S2N) ( $t$-test, $\left.t_{10}=2.8,{ }^{*} P=0.018\right)$. Basal width of sensillar types were the same between genders expected for sensilla chaetica (Supplementary Figure S2N) $(t$ test, $\left.t_{10}=2.9,{ }^{*} P=0.016\right)$.

\section{Electrophysiological Responses of $H$. cunea to Host Volatiles}

All chemicals were compared at the concentration of $1 \mu \mathrm{g} / \mu \mathrm{l}$, and gender bias for each chemical was shown in the heatmap (Figure 2B). Female moths showed significant higher responses than males when tested with dibutyl phthalate, $\beta$-ocimene, hexanal, cis-2-penten-1-ol, and cyclohexanene (Figure 2B) (GLM, dibutyl phthalate: $t=2.95, P=0.014$; $\beta$-ocimene: $t=3.78$, $P=0.0026$; hexanal: $t=4.30, P=0.001$; cis-2-penten-1-ol: $t=6.6$, $P<0.0001$; cyclohexanene: $t=3.22, P=0.0073$ ). While no male bias response was observed among all tested chemicals. Within the six new chemicals, linalyl butyrate, dibutyl phthalate, and palmitic acid elicited significantly higher EAG responses in both genders of adults when compared with most other chemicals (Figure 2B) [GLM and Tukey HSD, females: $F_{(16,85)}=10.8$, $P<0.0001$; males: $\left.F_{(16,107)}=14.5, P<0.0001\right]$.

In the later dosage response tests, significant differences in the EAG responses were observed among the doses for all

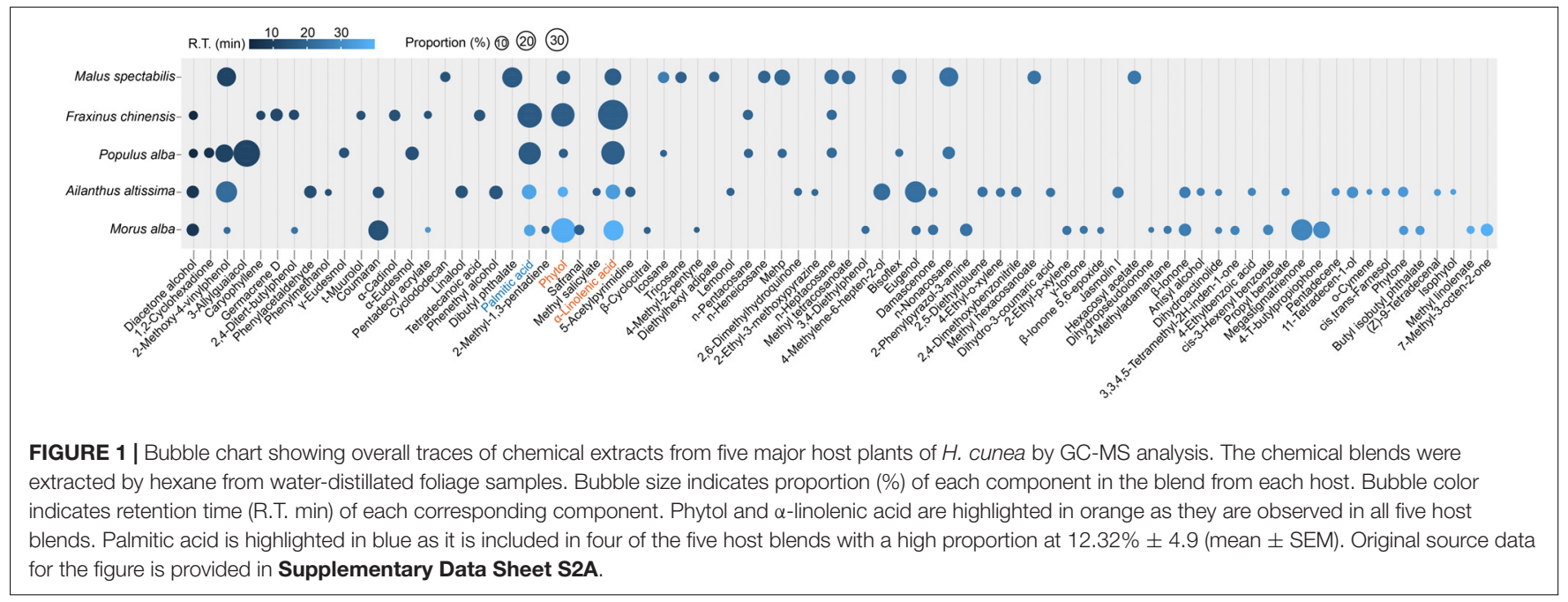




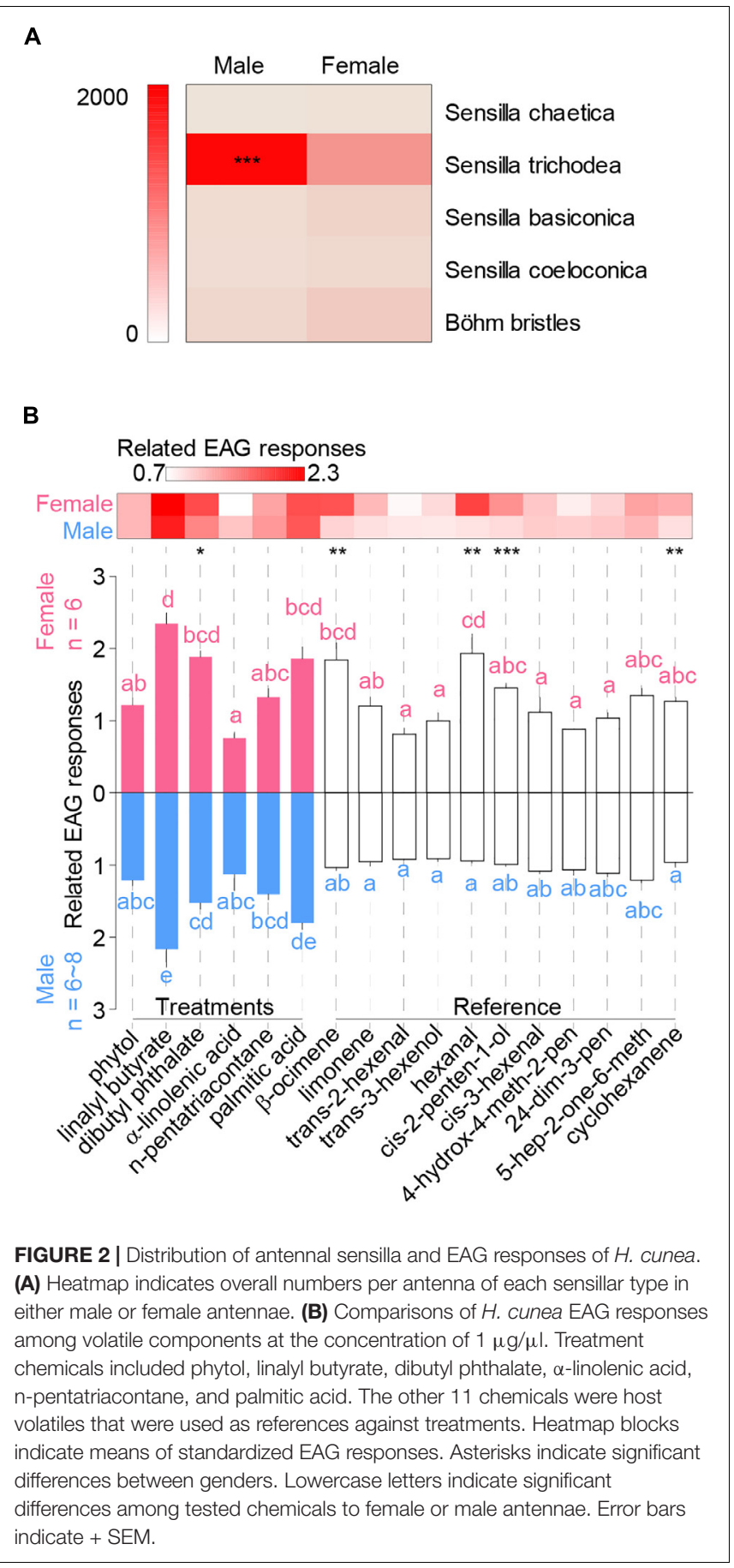

components (Figures 3A-F and Supplementary Figure S3). Strong and significant positive correlation was observed between EAG responses and dosages in males against $\alpha$-linolenic acid in males [Linear regression, $r^{2}=0.84, F_{(4,22)}=15.99, P=0.028$ ], n-pentatriacontane [Linear regression, $r^{2}=0.94, F_{(4,22)}=53.6$, $P=0.0053$ ], and palmitic acid [Linear regression, $r^{2}=0.85$, $\left.F_{(4,22)}=17.38, P=0.0251\right]$ (Figures 3D-F). Female EAG responses positively correlated with dosages when tested with palmitic acid (Linear regression, $r^{2}=0.89, F_{4,22}=23.51$,
$P=0.0167$ ) (Figure 3F). EAG responses of dibutyl phthalate $\left[F_{(4,25)}=5.6, P=0.002\right]$ and n-pentatriacontane in females $\left[F_{(4,25)}=17.9, P<0.0001\right]$ were decreased along with increase of dosages (Figures 3C,E). The highest responses for phytol were at the dosage of $0.1 \mu \mathrm{g} / \mu \mathrm{l}$, and a decrease was observed afterward (Figure 3A) [GLM and Tukey HSD, female: $F_{(4,25)}=11.6$, $P<0.0001$; male: $F_{(4,25)}=3.79, P=0.0153$ ].

When comparing the standardized EAG responses of both sexes of $H$. cunea to all six volatile compounds at the same concentration, male bias was observed for linalyl butyrate at 0.1-10 $\mu \mathrm{g} / \mu \mathrm{l}$, and $\alpha$-linolenic acid at 0.001 and $1 \mu \mathrm{g} / \mu \mathrm{l}$ (Figures 3B,D). In contrast, female bias was observed for phytol at $0.001 \mu \mathrm{g} / \mu \mathrm{l}$ and dibutyl phthalate at $0.01-0.1 \mu \mathrm{g} / \mu \mathrm{l}$ (Figures 3A,C). For n-pentatriacontane, female bias was observed at $0.001 \mu \mathrm{g} / \mu \mathrm{l}$, while male bias was observed during $0.1,1$, and $10 \mu \mathrm{g} / \mu \mathrm{l}$ (Figure 3E). Last, female and male moths did not show any significant sex-specific difference in their EAG responses to palmitic acid [two-way ANOVA, $F_{(4,50)}=1.157$, $P=0.93]$.

\section{Mating Rates Are Increased by the Volatiles}

In the reproductive behavioral assays, background mating rate was $22.5 \pm 3.69 \%$ (mean \pm SEM) in blank control. Solvent as paraffin oil had elicited mating rates at $22.86 \pm 2.19 \%$ and hexane was at $59.07 \pm 3.60 \%$ (Figure 4A). Compared to solvent, moth adults were more inclined to mate after they have been exposed to host-plant volatiles including dibutyl phthalate ( $t$-test, $\left.t_{6}=9.48, P<0.0001\right)$ and phytol ( $t$-test, $\left.t_{6}=6.33, P=0.0007\right)$, but no difference was observed between $n$-pentatriacontane and its solvent hexane ( $t$-test, $t_{6}=0.88, P=0.41$ ) (Figure 4A). The mating rates of moths exposed to dibutyl phthalate and phytol have reached $55.83 \pm 15.11 \%$ and $71.25 \pm 18.07 \%$, respectively, at $24 \mathrm{~h}$, more than twofold than the control and the paraffin oil solvent. On the other hand, palmitic acid decreased mating rates of adults compared with its solvent hexane ( $t$-test, $t_{6}=3.05$, $P=0.0226$ ) (Figure 4A).

Over $80 \%$ of the mated females conducted oviposition afterward when no chemical was applied (Figure 4B). However, all volatiles including two solvents did not influence the oviposition rates of $H$. cunea females [GLM and Dunnett test, $\left.F_{(8,27)}=0.49, P=0.85\right]$ (Figure 4B). Background fecundity of $H$. cunea was $516.6 \pm 45.87$ eggs (mean \pm SEM) per female in blank control treatment. When comparing the total number of eggs produced in different pairs, no significant difference was observed between the pairs exposed to volatiles and the control or the solvent [GLM and Dunnett test, $F_{(8,27)}=1.57$, $P=0.15]$ (Figure 4C).

\section{DISCUSSION}

Plant volatiles serve as essential cues to insects searching for resources, mates, and oviposition sites (Juma et al., 2016; Hanks et al., 2018; Houjun et al., 2018; Xu and Turlings, 2018). The reception of host-plant volatiles in Lepidoptera is accomplished through a highly sensitive chemosensory system on the antenna, 


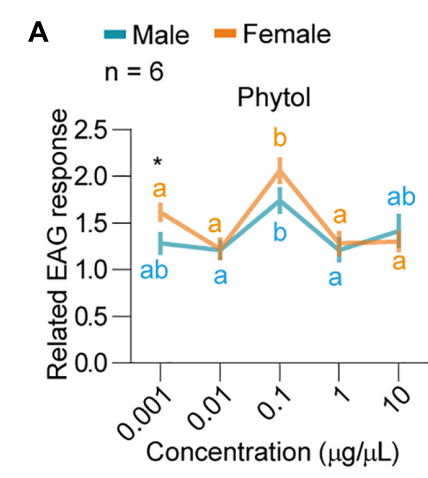

D

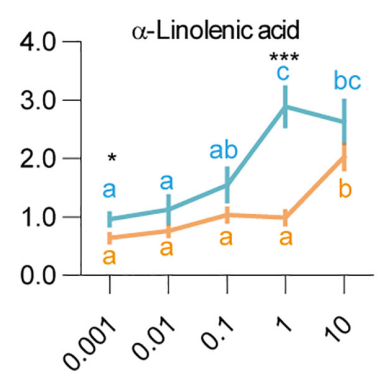

B

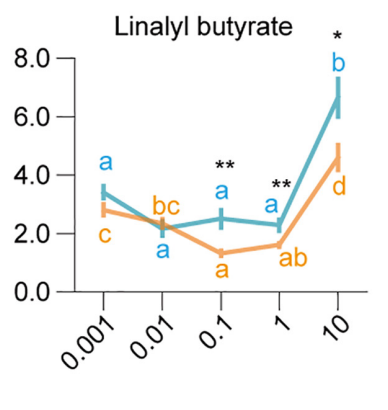

E

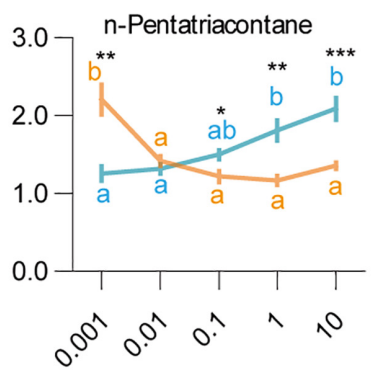

C

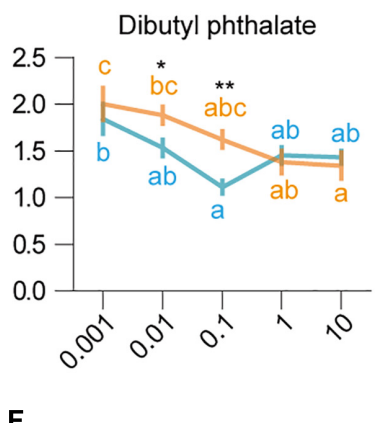

F

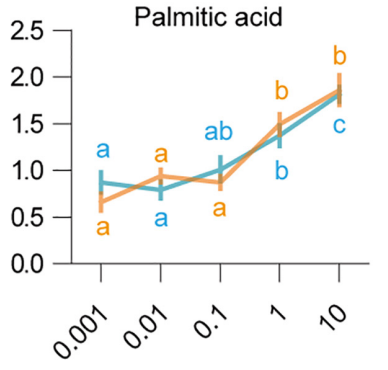

FIGURE 3 | Dosage responses of $H$. cunea adults EAG to selected host volatile components. Concentrations included $0.001,0.01,0.1,1$, and $10 \mu$ g/ $\mu$ l. (A) Adult EAG responses to phytol. Different lowercase letters indicate significant differences among tested dosages in both genders. Asterisk indicates significant difference between genders at $0.001 \mu \mathrm{g} / \mu \mathrm{l}$ concentration. (B) Adult EAG responses to linalyl butyrate. Differences in females and males were shown in different letters. Differences between genders at $0.1,1$, and $10 \mu \mathrm{g} / \mu \mathrm{l}$ were shown as asterisks. (C) Adult EAG responses to dibutyl phthalate. Differences in females and males were shown in different letters. Differences between genders at 0.01 and $0.1 \mu \mathrm{g} / \mu \mathrm{l}$ were shown as asterisks. (D) Adult EAG responses to $\alpha$-linolenic acid. Differences in females and males were shown in different letters. Differences between genders at 0.001 and $1 \mu \mathrm{g} / \mu \mathrm{l}$ were shown as asterisks. (E) Adult EAG responses to $\mathrm{n}$-pentatriacontane. Differences in females and males were shown in different letters. Differences between genders at $0.001,0.1,1$, and $10 \mu \mathrm{g} / \mu \mathrm{l}$ were shown as asterisks. (F) Adult EAG responses to palmitic acid. Differences in females and males were shown in different letters. All error bars indicate \pm SEM.

which is able to recognize and discriminate many different volatile chemicals (Gökçe et al., 2005; GöKçe et al., 2018; Molnár et al., 2017). The present electron microscopy study demonstrated that both sexes of $H$. cunea contain six different types of sensilla on their antenna, including sensilla trichodea, sensilla chaetica, sensilla basiconica, sensilla coeloconica, sensilla squamiformia, and sensilla böhm bristles, which revealed identical observations with previous studies (Zhang et al., 2019). Compared with other Lepidoptera, the morphology of the sensilla on the antenna of $H$. cunea is similar to related species, such as H. armigera, Phauda flammans Walker, Dogwood Borer, Holcocerus hippophaecolus Hua, and Tuta absoluta (Frank et al., 2010; Wang et al., 2015; Chang et al., 2016; Bawin et al., 2017; Liu et al., 2018). Antennal sensilla sexual dimorphism can be reflected by different length and width diameters of corresponding sensillar types (Zhang et al., 2019). Furthermore, we have also observed that distribution of sensillar types may vary between genders, which is intimately connected to feeding, mate location, oviposition, and other functions, indicating an especially ubiquitous form of intraspecific variation in moths (Allen et al., 2011). The function of sensilla has been reported to be primarily sensory, responsible for olfactory detection and perception of tactile signals. This involved various behaviors including habitat searching, host recognition, host location, host acceptance, copulation, and oviposition (Ansebo et al., 2005;
Meng et al., 2012; Zuo et al., 2015). The sensilla trichodea are the most conspicuous and the most numerically abundant type of sensilla on the antenna of $H$. cunea. It is frequently shown that sex pheromone components and plant volatiles are usually detected by sensilla trichodea (Kaissling, 2004; Meng et al., 2012; Chang et al., 2016; Liu et al., 2018a,b), suggesting that sensilla trichodea may be responsible for distinguishing pheromone components and plant volatiles. There is also ample evidence that sensilla basiconica participate in recognition for plant volatiles (Lopes et al., 2002; Yang et al., 2012). The information of the literature on the function of sensilla is instructional significant for peripheral coding of plant-associated compounds for H. cunea.

Electrophysiological recordings have been applied to the study of peripheral coding of host-plant volatiles in $H$. cunea (Tang et al., 2012, 2016). Both sexes of $H$. cunea moths showed high sensitivity to the compounds tested that are potentially involved in host-moth interactions. These results are relatively consistent with a preliminary study; volatiles and their dosages elicited electro-physiological responses in the antenna of male and female moths (Tang et al., 2012, 2016). On the other hand, responses to olfactory cues in behavioral assays are not always consistent with EAG tests (Choo et al., 2018; Xiu et al., 2019). Our mating tests also revealed that linalyl butyrate and $\alpha$-linolenic acid did not influence mating rates in $H$. cunea, although they 


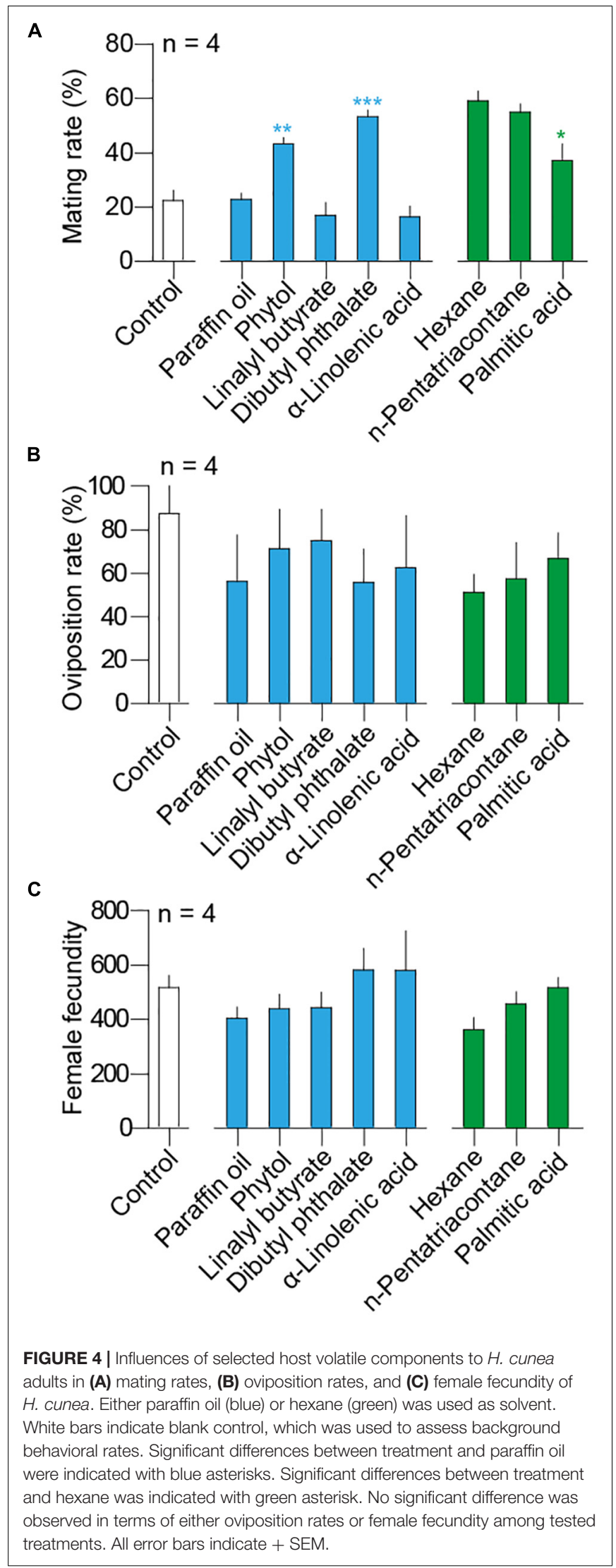

exhibited significant EAG amplitudes. While we cannot exclude the possible role of these two chemicals in terms of feeding or host location, we still need to be cautious when talking about bioactive compounds without substantial evidence from behavioral tests. Furthermore, significant differences in the EAG responses were observed among the doses, which is consistent with other studies (Lu et al., 2017; Oseiowusu et al., 2020). For instance, the highest EAG responses were found with linalyl butyrate, $\alpha$-linolenic acid, and palmitic acid at the highest dose; in contrast, the compounds dibutyl phthalate and n-pentatriacontane elicited a more robust response at lower doses. This differential odor sensitivity could be attributed to the presence of specific receptors that respond to particular categories of chemicals (Shields and Hildebrand, 2001). The higher EAG responses were found with linalyl butyrate than all other compounds in both sexes of the moths. Plant-associated ester compounds are more efficient for other moths, such as pear ester in C. pomonella, Rhagoletis, and Dysaphis plantaginea (Light et al., 2001; Linn et al., 2003; Van Tol et al., 2009).

The results obtained in our electrophysiological experiment prompted us to investigate the function of the compounds derived from plants on the reproduction system. In single-pair courtship assays, we found that the mating rate of $H$. cunea exposed to host-derived volatiles dibutyl phthalate and phytol were more than twice that from the control and paraffin oil. This is consistent with what has been found in the previous study regarding the effects of $\beta$-ocimene (host volatile) on mating rates of $H$. cunea moth pairs (Tang et al., 2016). These results suggested that host-derived volatile cues could promote mating behaviors in $\mathrm{H}$. cunea moths. The same is true for females of Plutella xylostella, which rely heavily on host-plant volatiles for mating (Wee, 2016). Similarly, females of certain tephritid fruit fly species (Diptera: Tephritidae) show increased receptivity to mating after exposure to host fruit volatiles (Gerofotis et al., 2013; Bachmann et al., 2015). One of the most important factors is that females could emit more sex pheromone while exposing to plant volatiles, such as in cabbage looper moth Trichoplusia (Landolt et al., 1994), the corn earworm moth Helicoverpa zea (Raina et al., 1992), and the tobacco budworm Heliothis virescens (Raina et al., 1997). Also, the plant-provided signals deliver spatial information for insects to find mates. For example, plant volatiles are likely to serve as attractants to insects over a larger spatial range and pheromones are more likely to help guide the insects over a relatively short distance to mate in parasitoids (Xu and Turlings, 2018). Host-derived volatiles play an important role as oviposition stimulant for Lepidopterans, such as tobacco hornworm Manduca sexta, Ostrinia latipennis, C. pomonella, and the stem borer Busseola fusca (Mechaber et al., 2002; Li and Ishikawa, 2006; Lombarkia and Derridj, 2008; Juma et al., 2016). However, our results showed that female oviposition rates and fecundity of $H$. cunea did not show sensitivity toward the volatiles from host plants. In all, potential ecological-based trapping method can be developed by utilizing these common volatiles from host plants of $H$. cunea, and an olfactory peripheral coding mechanism and the molecular basis of this pest are worth looking into by future studies. 


\section{DATA AVAILABILITY STATEMENT}

All datasets generated for this study are included in the article/Supplementary Material.

\section{AUTHOR CONTRIBUTIONS}

$\mathrm{P}-\mathrm{HB}$ and RT designed the study. P-HB, H-MW, and ML conducted the SEM tests. P-HB, H-MW, and RT conducted the electroantennogram experiments. B-SL, B-ML, and X-SG conducted the indoor bioassays. RT, P-HB, and H-MW analyzed the data and drafted the manuscript with contributions from all authors.

\section{FUNDING}

This research was funded by the Creative Research for Young Scientists of Tianjin Academy of Agricultural Sciences (China) (2020008), the Central Public-interest Scientific Institution Basal

\section{REFERENCES}

Abdullah, Z. S., Greenfield, B. P., Ficken, K. J., Taylor, J. W. D., Wood, M., and Butt, T. M. (2015). A new attractant for monitoring western flower thrips, Frankliniella occidentalis in protected crops. Springerplus 4:89. doi: 10.1186/ s40064-015-0864-3

Allen, C. E., Zwaan, B. J., and Brakefield, P. M. (2011). Evolution of sexual dimorphism in the Lepidoptera. Annu. Rev. Entomol. 56, 445-464. doi: 10.1146/ annurev-ento-120709-144828

Ansebo, L., Ignell, R., Löfqvist, J., and Hansson, B. S. (2005). Responses to sex pheromone and plant odours by olfactory receptor neurons housed in sensilla auricillica of the codling moth, Cydia pomonella (Lepidoptera: Tortricidae). J. Insect. Physiol. 51, 1066-1074. doi: 10.1016/j.jinsphys.2005.05.003

Bachmann, G. E., Segura, D. F., Devescovi, F., Juárez, M. L., Ruiz, M. J., Vera, M. T., et al. (2015). Male sexual behavior and pheromone emission is enhanced by exposure to guava fruit volatiles in Anastrepha fraterculus. PLoS One 10:e0124250. doi: 10.1371/journal.pone.0124250

Bai, P. H., Liu, B. S., Gu, X. S., Yu, J. P., Huo, J. F., and Shi, Q. J. (2018a). The volatile components of the Malus spectabilis and the EAG responses of the Hyphantria cunea drury. China Fruits 6, 63-67.

Bai, P. H., Liu, B. S., Jia, A. J., Bai, Y. C., Feng, Y. R., and Yu, J. P. (2017). Research progress on biological control of Hyphantria cunea in China. China Fruits 6, 65-69.

Bai, P. H., Xiang, W. F., Liu, B. S., Li, M., and Yu, J. P. (2018b). The volatile components of the Robinta pseudoacacia and the EAG responses of the Hyphantria cunea Drury. Shandong. Agric. Sci. 50, 103-108.

Bawin, T., Collard, F., De Backer, L., Yaroua, B. B., Compère, P., Francis, F., et al. (2017). Structure and distribution of the sensilla on the antenna of Tuta absoluta (Lepidoptera: Gelechiidae). Micron 96, 16-28. doi: 10.1016/j.micron.2017. 01.008

Bisch-Knaden, S., Dahake, A., Sachse, S., Knaden, M., and Hansson, B. S. (2018). Spatial representation of feeding and oviposition odors in the brain of a hawkmoth. Cell. Rep. 22, 2482-2492. doi: 10.1016/j.celrep.2018.01.082

Bleeker, P. M., Diergaarde, P. J., Ament, K., Schütz, S., Johne, B., Dijkink, J., et al. (2011). Tomato-produced 7-epizingiberene and R-curcumene act as repellents to whiteflies. Phytochemistry 72, 68-73. doi: 10.1016/j.phytochem. 2010.10.014

Chang, H. T., Guo, M. B., Wang, B., Liu, Y., Dong, S. L., and Wang, G. R. (2016). Sensillar expression and responses of olfactory receptors reveal different peripheral coding in two Helicoverpa species using the same pheromone components. Sci. Rep. 6:18742. doi: 10.1038/srep18742
Research Fund (No. Y2020GH21-1) of China, the Agricultural Transformation of Scientific and Technological Achievements of Tianjin: Introduction and Demonstration of sex pheromone Synergist of Hyphantria cunea (201901070), the President fund of Tianjin Academy of Agricultural Sciences (China) (16006), and Tianjin Fruits and Forest Research System - Quality Control and Safety (ITTFPRS2018008).

\section{ACKNOWLEDGMENTS}

We thank Prof. Zhong-Ning Zhang for providing comments and suggestions on improving our manuscript. We also thank B.F.A. Xiao-Qian Bao for technical support on development of graphics.

\section{SUPPLEMENTARY MATERIAL}

The Supplementary Material for this article can be found online at: https://www.frontiersin.org/articles/10.3389/fphys. 2020.00486/full\#supplementary-material

Chen, C., Wei, X., Xiao, H., He, H., Xia, Q., and Xue, F. (2014). Diapause induction and termination in Hyphantria cunea (Drury) (Lepidoptera: Arctiinae). PLoS One 9:e98145. doi: 10.1371/journal.pone.0098145

Choo, Y. M., Xu, P., Hwang, J. K., Zeng, F., Tan, K., Bhagavathy, G., et al. (2018). Reverse chemical ecology approach for the identification of an oviposition attractant for Culex quinquefasciatus. Proc. Natl. Acad. Sci. U.S.A. 115, 714-719. doi: 10.1073/pnas.1718284115

Frank, D. L., Leskey, T. C., and Bergh, J. C. (2010). Morphological characterization of antennal sensilla of the dogwood borer (Lepidoptera: Sesiidae). Ann. Entomol. Soc. Am. 103, 993-1002. doi: 10.1603/an09182

Gerofotis, C. D., Ioannou, C. S., and Papadopoulos, N. T. (2013). Aromatized to find mates: $\alpha$-pinene aroma boosts the mating success of adult olive fruit flies. PLoS One 8:e81336. doi: 10.1371/journal.pone.0081336

Gökçe, A., Stelinski, L. L., and Whalon, M. E. (2005). Behavioral and electrophysiological responses of leafroller moths to selected plant extracts. Environ. Entomol. 34, 1426-1432. doi: 10.1603/0046-225x-34.6.1426

GöKçe, A., Stelinski, L. L., and Whalon, M. E. (2018). The effects of non-host plant extracts on electroantennogram responses, behavior and egg hatching of codling moth. Cydia pomonella. J. Pest. Sci. 91, 681-690. doi: 10.1007/s10340018-0953-5

Gregg, P. C., Del Socorro, A. P., Hawes, A. J., and Binns, M. R. (2016). Developing bisexual attract-and-kill for polyphagous insects: ecological rationale versus pragmatics. J. Chem. Ecol. 42, 666-675. doi: 10.1007/s10886-0160725-8

Gundappa, Jayanthi, K., Auarde, R. M., Kempraj, V., Ravindra, K. V., Bhaktavatsalam, N., et al. (2016). Behavioral and electrophysiological responses of mango hopper, Idioscopus nitidulus (Walker) (Hemiptera: Cicadellidae) to host cues. Pest. Manag. Hortic. Ecosystems. 22, 118-122.

Guo, H., and Wang, C. Z. (2019). The ethological significance and olfactory detection of herbivore-induced plant volatiles in interactions of plants herbivorous insects and parasitoids. Arthropod Plant Inte. 13, 161-179. doi: 10.1007/s11829-019-09672-5

Hanks, L. M., Mongold-Diers, J. A., Atkinson, T. H., Fierke, M. K., Ginzel, M. D., Graham, E. E., et al. (2018). Blends of pheromones, with and without host plant volatiles, can attract multiple species of cerambycid beetles simultaneously. J. Econ. Entomol. 111, 716-724. doi: 10.1093/jee/tox373

Hill, A. S., Kovalev, B. G., Nikolaeva, L. N., and Roelofs, W. L. (1982). Sex pheromone of the fall webworm moth. Hyphantria cunea. J. Chem. Ecol. 8, 383-396. doi: 10.1007/BF00987787

Hou, Z. Y., and Yan, F. S. (1995). Electroantennogram response of Lysiphlebia japonica Ashmead (Homoptera: Aphididae) to some cotton plant volatiles and 
cotton aphid pheromones. Entomol. Sin. 2, 253-264. doi: 10.1111/j.1744-7917. 1995.tb00047.x

Houjun, T., Lin, S., Chen, Y., Chen, Y., Zhao, J., Gu, X., et al. (2018). Electroantennogram responses to plant volatiles associated with fenvalerate resistance in the diamondback Moth. Plutella xylostella (Lepidoptera: Plutellidae). J. Econ. Entomol. 111, 1354-1360. doi: 10.1093/jee/toy022

Joseph, R. M., and Carlson, J. R. (2015). Drosophila chemoreceptors: a molecular interface between the chemical world and the brain. Trends Genet. 31, 683-695. doi: 10.1016/j.tig.2015.09.005

Juma, G., Clément, G., Ahuya, P., Hassanali, A., Derridj, S., Gaertner, C., et al. (2016). Influence of host-plant surface chemicals on the oviposition of the cereal stemborer Busseola Fusca. J. Chem. Ecol. 42, 394-403. doi: 10.1080/13607863. 2016.1268095

Kaissling, K. E. (2004). Physiology of pheromone reception in insects (an example of moths). Anir 6, 73-91. doi: 10.1371/journal.pone.0152147

Kergunteuil, A., Sébastien, D., Danner, H., van Dam, N. M., and Cortesero, A. M. (2015). Characterizing volatiles and attractiveness of five brassicaceous plants with potential for a 'push-pull' strategy toward the cabbage root fly. Delia Radicum. J. Chem. Ecol. 41, 330-339. doi: 10.1007/s10886-015-0575-9

Kim, I. K., Park, Y. K., and Koh, S. H. (2011). Chalcidoid wasps parasitizing pupae of fallwebworm. Hyphantria cunea (Drury), in South Korea. Entomol. Res. 41, 278-278. doi: 10.1111/j.1748-5967.2011.00373.x

Landolt, P. J., Heath, R. R., Millar, J. G., Davishernandez, K. M., Dueben, B. D., and Ward, K. E. (1994). Effects of host plant, Gossypium hirsutum L., on sexual attraction of cabbage looper moths, Trichoplusia ni (Hübner) (Lepidoptera: Noctuidae). J. Chem. Ecol. 20, 2959-2974. doi: 10.1007/bf02098402

Li, G., and Ishikawa, Y. (2006). Leaf epicuticular was chemicals of the Japanese knotweed Fallopia japonica as oviposition stimulants for Ostrinia latipennis. J. Chem. Ecol. 32, 595-604. doi: 10.1007/s10886-005-9022-7

Li, W. Z., Yuan, G. H., Sheng, C. F., and Guo, X. R. (2005). Active compounds in Populus nigra $\mathrm{L}$. wilted leaves responsible for attracting Helicoverpa armigera (Hübner) (Lep: Noctuidae) and new agaropectin formulation. J. App. Entomol. 129, 557-562. doi: 10.1111/j.1439-0418.2005.01008.x

Light, D. M., Knight, A. L., Henrick, C. A., Rajapaska, D., Lingren, B., Dickens, J. C., et al. (2001). A pear-derived kairomone with pheromonal potency that attracts male and female codling moth, Cydia pomonella (L.). Naturwissenschaften 88 , 333-338. doi: 10.1007/s001140100243

Linn, C., Feder, J. L., Nojima, S., Dambroski, H. R., Berlocher, S. H., and Roelofs, W. (2003). Fruit odor discrimination and sympatric host race formation in Rhagoletis. Proc. Natl. Acad. Sci. U.S.A. 100, 11490-11493. doi: 10.1073/pnas. 1635049100

Liu, J. Y., Zhang, Y. J., Huang, J. Y., Dong, Z. S., Duan, Y. B., Lu, W., et al. (2018). Ultrastructural observations of antennal sensilla in Phauda flammans Walker (Lepidoptera: Zygaenidae). J. Entomol. Sci. 53, 281-294.

Liu, W., Jiang, X. C., Cao, S., Yang, B., and Wang, G. R. (2018a). Functional studies of sex pheromone receptors in Asian corn borer Ostrinia furnacalis. Front. Physiol. 9:591. doi: 10.3389/fphys.2018.00591

Liu, Y. P., Liu, Y., Jiang, X. C., and Wang, G. R. (2018b). Cloning and functional characterization of three new pheromone receptors from the diamondback moth Plutella xylostella. J. Insect. Physiol. 107, 14-22. doi: 10.1016/j.jinsphys. 2018.02.005

Lombarkia, N., and Derridj, S. (2008). Resistance of apple trees to Cydia pomonella egg-laying due to leaf surface metabolites. Entomol. Exp. Appl. 128, 57-65. doi: $10.1111 / \mathrm{j} .1570-7458.2008 .00741 . \mathrm{x}$

Lopes, O., Barata, E. N., Mustaparta, H., and Araújo, J. (2002). Fine structure of antennal sensilla basiconica and their detection of plant volatiles in the eucalyptus woodborer, Phoracantha semipunctata Fabricius (Coleoptera: Cerambycidae). Arthropod. Struct. Dev. 31, 1-13. doi: 10.1016/s1467-8039(02) 00011-7

Lu, Y. H., Liu, K., Zheng, X., and Lu, Z. X. (2017). Electrophysiological responses of the rice striped stem borer Chilo suppressalis to volatiles of the trap plant vetiver grass (Vetiveria zizanioides L.). J. Integr. Agric. 11, 2525-2533. doi: 10.1016/s2095-3119(17)61658-7

Mechaber, W. L., Capaldo, C. T., and Hilderbrand, J. G. (2002). Behavioural response of adult female tobacco hornworm, Manduca sexta, to host plant volatiles change with age and mating status. J. Insect. Sci. 2:5.

Meng, Z. J., Yan, S. C., Yang, C. P., and Ruan, C. (2012). Asymmetrical distribution of antennal sensilla in the female Anastatus japonicus Ashmead (Hymenoptera: Eupelmidae). Microsc. Res. Tech. 75, 1066-1075. doi: 10.1002/jemt.22032
Molnár, B. P., Tóth, Z., and Kárpáti, Z. (2017). Synthetic blend of larval frass volatiles repel oviposition in the invasive box tree moth, Cydalima perspectalis. J. Pest. Sci. 90, 873-885. doi: 10.1007/s10340-017-0837-0

Natale, D., Mattiacci, L., Pasqualini, E., and Dorn, S. (2004). Apple and peach fruit volatiles and the apple constituent butyl hexanoate attract female oriental fruit moth, Cydia molesta, in the laboratory. J. App. Entomol. 128, 22-27. doi: 10.1046/j.1439-0418.2003.00802.x

Oseiowusu, J., Vuts, J., Caulfield, J. C., Woodcock, C. M., Withall, D. M., Hooper, A. M., et al. (2020). Identification of semiochemicals from cowpea, Vigna unguiculata, for low-input management of the legume pod borer, Maruca vitrata. J. Chem. Ecol. 1, 1-11. doi: 10.1007/s10886-020-01149-7

Paschen, M. A., Schiff, N. M., and Ginzel, M. D. (2012). Role of volatile semiochemicals in the host and mate location behavior of Mallodon dasystomus (Coleoptera: Cerambycidae). J. Insect. Behav. 25, 569-577. doi: 10.1007/s10905012-9321-0

Raina, A. K., Jackson, M. D., and Severson, R. F. (1997). Increased pheromone production in wild tobacco budworm (Lepidoptera: Noctuidae) exposed to host plants and host chemicals. Environ. Entomol. 26, 101-105. doi: 10.1093/ee/26. 1.101

Raina, A. K., Kingan, T. G., and Mattoo, A. K. (1992). Chemical signals from host plant and sexual behavior in a moth. Science 255, 592-594. doi: 10.1126/science. 255.5044.592

Reed, H. C., and Landolt, P. J. (2002). Attraction of mated female codling moths (Lepidoptera: Tortricidae) to apples and apple odor in a flight tunnel. Flo. Entomol. 85, 324-329. doi: 10.1653/0015-4040(2002)085\%5B0324:aomfcm\% 5D2.0.co; 2

Saruhan, I., Akca, I., and Kushiyev, R. (2014). Toxicity of some biopesticides to the fall webworm, Hyphantria cunea Durry (Lepidoptera: Arctidae). Egypt. J. Biol. Pest. Control 24, 255-257.

Schneider, D. (1964). Insect antenna. Annu. Rev. Entomol. 9, 103-122.

Schowalter, T. D., and Ring, D. R. (2017). Biology and management of the fall webworm, Hyphantria cunea (Lepidoptera: Erebidae). J. Integr. Pest. Manag. $8,1-6$.

Shelly, T. (2001). Exposure to $\alpha$-copaene and $\alpha$-copaene-containing oils enhances mating success of male Mediterranean fruit flies (Diptera: Tephritidae). Ann. Entomol. Soc. Am. 94, 497-502. doi: 10.1603/0013-8746(2001)094\%5B0497: etcacc\%5D2.0.co;2

Shields, V. D. C., and Hildebrand, J. G. (2001). Responses of a population of antennal olfactory receptor cells in the female moth Manduca sexta to plantassociated volatile organic compounds. J. Comp. Physiol. A 186, 1135-1151. doi: 10.1007/s003590000165

Siderhurst, M. S., and Jang, E. B. (2006). Female-biased attraction of oriental fruit fly, Bactrocera dorsalis (Hendel), to a blend of host fruit volatiles from Terminalia catappa L. J. Chem. Ecol. 32, 2513-2524. doi: 10.1007/s10886-0069160-6

Singh, A. K., and Mullick, S. (2010). Leaf volatiles as attractants for neonate Helicoverpa armigera Hbn. (Lep: Noctuidae) larvae. J. Appl. Entomol. 126, 14-19. doi: 10.1046/j.1439-0418.2002.00600.x

Su, M. W., Fang, Y. L., Tao, W. Q., Yan, G. Z., Ma, W. E., and Zhang, Z. N. (2008). Identification and field evaluation of the sex pheromone of an invasive pest, the fall webworm Hyphantria cunea in China. Chin. Sci. Bull. 53, 555-560. doi: 10.1007/s11434-008-0124-9

Tang, R., Zhang, F., and Zhang, Z. N. (2016). Electrophysiological responses and reproductive behaviour of fall webworm moths (Hyphantria cunea Drury) are influenced by volatile compounds from its mulberry Host (Morus alba L.). Insects 7:19. doi: 10.3390/insects7020019

Tang, R., Zhang, J. P., and Zhang, Z. N. (2012). Electrophysiological and behavioural responses of male fall webworm moths (Hyphantria cunea Drury) to herbivory-induced mulberry (Morus alba) leaf volatiles. PLoS One 7:e49256. doi: 10.1371/journal.pone.0049256

Turlings, T. C. J., and Erb, M. (2018). Tritrophic interactions mediated by herbivore-induced plant volatiles: mechanisms, ecological relevance, and application potential. Annu. Rev. Entomol. 1, 433-452. doi: 10.1146/annurevento-020117-043507

Van Tol, W. H. M., Helsen, H. H. M., Griepink, F. C., and de Kogel, W. J. (2009). Female-induced increase of host-plant volatiles enhance specific attraction of aphid male Dysaphis plantaginea (Homoptera: Aphididae) to the sex pheromone. Bull. Entomol. Res. 99, 593-602. doi: 10.1017/S000748530900 6634 
Wang, R., Zhang, L., Xu, L. L., Zong, S. X., and Luo, Y. Q. (2015). Sensilla on the antenna and ovipositor of the sea buckthorn carpenter moth, Holcocerus hippophaecolus Hua et al. (Lepidoptera: Cossidae). Neotrop. Entomol. 44, 68-76. doi: 10.1007/s13744-014-0258-1

Wee, S. L. (2016). Effects of conspecific herbivory and mating status on host searching and oviposition behavior of Plutella xylostella (Lepidoptera: Plutellidae) in relation to its host, Brassica oleracea (Brassicales: Brassicaceae). Flo. Entomol. 99, 159-165. doi: 10.1653/024.099.sp119

Xiu, C. L., Pan, H. S., Liu, B., Luo, Z. X., Williams, L., Yang, Y. Z., et al. (2019). Perception of and behavioural responses to host plant volatiles for three Adelphocoris species. J. Chem. Ecol. 45, 779-788. doi: 10.1007/s10886019-01102-3

$\mathrm{Xu}, \mathrm{H}$., and Turlings, T. C. J. (2018). Plant volatiles as mate-finding cues for insects. Trends Plant. Sci. 23, 100-111. doi: 10.1016/j.tplants.2017.11.004

$\mathrm{Xu}$, Q., Séverin, H., Lopes, T., Zhang, Y., Bodson, B., Chen, J. L., et al. (2018). A push-pull strategy to control aphids combines intercropping with semiochemical releases. J. Pest. Sci. 91, 93-103. doi: 10.1007/s10340-0170888-2

Xu, X. X., Cai, X. M., Bian, L., Luo, Z. X., Xin, Z. J., and Chen, Z. M. (2001). Electrophysiological and behavioral responses of Chrysopa phyllochroma (Neuroptera: Chrysopidae) to plant volatiles. Environ. Entomol. 44, 1425-1433. doi: $10.1093 /$ ee/nvv106

Yan, H., Zeng, J., and Zhong, G. (2015). The push-pull strategy for citrus psyllid control. Pest. Manag. Sci. 71, 893-896. doi: 10.1002/ps.3915

Yang, B. S., Wang, H., Zhao, Q., and Liang, W. (2010). Investigation of Hyphantria cunea host among urban afforestation tree species in Jinan City*. J. University Ji. 3,

Yang, Y., Krieger, J., Zhang, L., and Breer, H. (2012). The olfactory co-receptor Orco from the migratory locust (Locusta migratoria) and the desert locust (Schistocerca gregaria): identification and expression pattern. Int. J. Bio. Sci. 8, 159-170. doi: 10.7150/ijbs.8.159

Yang, Z. Q., Wang, X. Y., Wei, J. R., Qu, H. R., and Qiao, X. R. (2008). Survey of the native insect natural enemies of Hyphantria cunea (Drury) (Lepidoptera: Arctiidae) in China. Bull. Entomol. Res. 98, 293-302. doi: 10.1017/ S0007485308005609
Yang, Z. Q., Wei, J. R., and Wang, X. Y. (2006). Mass rearing and augmentative releases of the native parasitoid Chouioia cunea for biological control of the introduced fall webworm Hyphantria cunea in China. Biocontrol. 51, 401-418. doi: 10.1007/s10526-006-9010-z

Zacharuk, R. Y. (1980). Ultrastructure and fuction of insect chemsensilla. Annu. Rev. Entomol. 25, 27-47.

Zhang, J., Fu, L., Cheng, B., and Sun, S. (2019). Morphological characteristics of antennal sensilla in Hyphantria cunea (Drury) (Lepidoptera: Erebidae). T. Am. Entomol. Soc. 145, 421-434.

Zhang, L. W., Kang, K., Jiang, S. C., Zhang, Y. N., Wang, T. T., Zhang, J., et al. (2016a). Analysis of the antennal transcriptome and insights into olfactory genes in Hyphantria cunea (Drury). PLoS One 11:e0164729. doi: 10.1371/ journal.pone.0164729

Zhang, L. W., Kang, K., Liu, Y. J., Zhang, J., Sun, L., Zhang, C., et al. (2016b). Evaluation of Beauveria bassiana isolates as potential agents for control of Hyphantria cunea (Lepidoptera: Arctiidae). Acta Entomol. Sin. 59, 111-118.

Zhu, G. P., Pan, L., Zhao, Y., Zhang, X., Wang, F., Yu, Y., et al. (2017). Chemical investigations of volatile kairomones produced by Hyphantria cunea (Drury), a host of the parasitoid Chouioia cunea Yang. Bull. Entomol. Res. 107, 234-240. doi: 10.1017/S0007485316000833

Zuo, T. T., Wang, M. Y., Zhang, J., Li, L. M., Li, D. F., and Zhang, X. J. (2015). Antennal sensillar of Cryptorhynchus Lapathi L. (Coleoptera: Curculionidae). Entomol. News 125, 199-213.

Conflict of Interest: The authors declare that the research was conducted in the absence of any commercial or financial relationships that could be construed as a potential conflict of interest.

Copyright (c) 2020 Bai, Wang, Liu, Li, Liu, Gu and Tang. This is an open-access article distributed under the terms of the Creative Commons Attribution License (CC BY). The use, distribution or reproduction in other forums is permitted, provided the original author(s) and the copyright owner(s) are credited and that the original publication in this journal is cited, in accordance with accepted academic practice. No use, distribution or reproduction is permitted which does not comply with these terms. 